
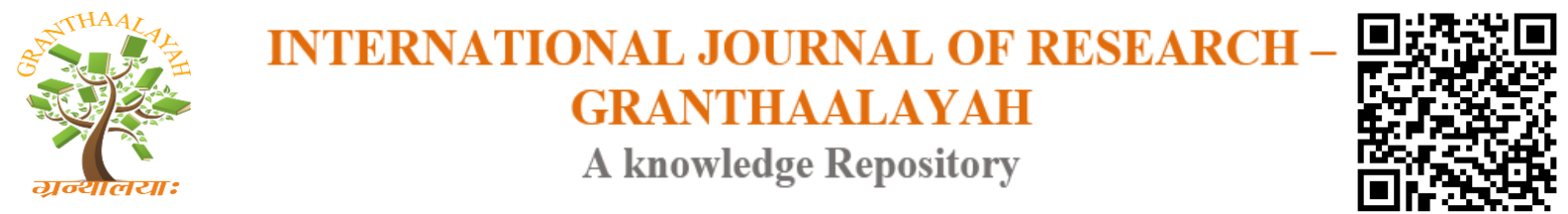

Social

\title{
AN ANALYSIS OF THE MULTI - WORD EXPRESSIONS USED IN SPORTS NEWS STORIES: A CASE STUDY OF TEN SPORTS NEWS STORIES SELECTED FROM THE BANGKOK POST
}

\author{
Ms. Sutthinan Ingbarmee ${ }^{* 1}$, Dr. Prommintra Kongkeaw ${ }^{2}$ \\ ${ }^{*} 1,2$ Departmemt of English, Ubon Ratchathani Rajabhat University, THAILAND
}

DOI: https://doi.org/10.29121/granthaalayah.v4.i10.2016.2496

\section{ABSTRACT}

The purposes of the study were to analyze the structure of the multi-word expressions used in sports news stories and to study types of the multi - word expressions used in sports news stories. The subjects of this study were10 sport news stories including five football news, three tennis news and two boxing news collected from the Bangkok Post from 27 September to 14 November 2014.The percentage was used for data analysis. The study found that the patterns of the multi-word expressions in those news stories could be detailed as follows. The structure used with the highest occurrence was Adjective + Noun, Asian Games; it accounts for 43.02\% in ten news stories. The pattern mostly used in a second ranking was Noun + Noun, seasonending tournament; it accounts for $12.83 \%$. The structure ranked third in its use in the selected news stories was Noun +'s+ Noun, Spain's Ferrer; it made up 18.11\%. The structure came in fourth was Noun +of + Noun, Kuldep Singh of India; it represented 12.45\%. The structure came in fifth was Noun +Noun + Noun, World number three; it represented $7.17 \%$. Last, the structure Adjective + Noun+ Noun, Five Thai fighters, was the least used; it accounts for only $6.42 \%$ in ten subjects.

Keywords:

Multi - word expressions, Online English News Website, Sports News.

Cite This Article: Ms. Sutthinan Ingbarmee, and Dr. Prommintra Kongkeaw, "AN ANALYSIS OF THE MULTI - WORD EXPRESSIONS USED IN SPORTS NEWS STORIES: A CASE STUDY OF TEN SPORTS NEWS STORIES SELECTED FROM THE BANGKOK POST" International Journal of Research - Granthaalayah, Vol. 4, No. 10 (2016): 91-96.

\section{INTRODUCTION}

In the world of communication, the newspaper is considered a popular source of information that is readily available and accessible to every person. It provides local, national and global news, entertainment, advertisement, and sports to update readers' knowledge about social, economic, political, literary and scientific issues, to name a few (Thanomsak, 1998). 
Newspapers are one of the main media sources which have an important role in human life since they give people information about the surrounding situation or what is happening in the world. The newspaper even becomes the concern of the linguistics for the way information is written and presented to the readers and what meaning thein formation can give. The newspaper has the potential power in our society because it determines what news would be given to the society or who can get into the paper (Surasak, 2011).

In Thailand, there are both Thai and English newspapers which are published and sold. The English newspapers are popular for some groups of people in Thailand such as businessmen, foreigners; expatriate workers and some educated Thai people (Surasak, 2011).There are two well-known English language newspapers in Thailand. They are the daily English language newspapers: the Bangkok Post and the Nation. Both are equivalent in both quality and quantity of news information. Over the years, both newspapers have won many awards from International Trade Organizations, which guarantees that both newspapers are the leading newspapers and are among the best in Asia (Prado, 2003). Their target readers are not only foreigners and expatriates but nearly 70 percent of the main readers are Thais of a variety of occupations (Gold, 1991), including teachers of English, who make use of these newspapers as teaching materials in the classroom and a supplement to help Thai students to improve their English proficiency and to learn of the current events in the country and around the world.

Multi - word expressions are problematic both in teaching and learning a foreign language since a multi - word expression is a sequence of two or more words. Additionally, multi - word expressions are an outcome of lexical and semantic changes as a result of fossilization in written text as suggested by Moon (1997). Further, Read (2000) states that multi - word expressions have not been given much attention when vocabulary knowledge is assessed. Conversely, there are two methods of examining multi - word expressions by consulting speakers and by analyzing their occurrences. Multi - word expressions are often used in common language for expressing ideas and thoughts and it is also hard extract them into a single word (Villavicencio et al, 2004). Moreover, multi - word expressions appear in different structures and languages (Baldwin et al, 2003) It is obvious that multi - word expressions (MWEs) are a key component for developing English reading ability.

As mentioned above, people have to read useful information to gain a lot of knowledge about news. One type of authentic reading materials in English is a newspaper. A newspaper is one of the most interesting types of English reading for learners because it is used as a source of up- to - date English language to extend their reading after they conclude their classroom study. Therefore, the researcher intends to conduct research on "The Multi Word Expression Used in News Headlines in the Bangkok Post to help the readers especially those who are non-native speakers of English to scan and understand the English sports news headlines more quickly.

\section{MATERIALS AND METHODS}

\section{SAMPLES OF THE STUDY}

The samples of the study were ten selected sports news stories selected from 27 September to 14 November 2014.They were divided into five football news stories, three tennis news stories and 
two boxing news stories. They were purposely collected from 27 September to 14 November 2014. The source of the samples used is the online Bangkok Post.

\section{DATA COLLECTION}

The sports news stories totaling ten were purposely collected from the online Bangkok Post in November 2014. The researcher specifically selected the sports news stories of five football news stories, three tennis news stories and two boxing news stories. The sports news stories selected in the study are:

1) S.Korea beat Japan to reach Asian Games football semis

2) Kiatisak's men face Iraq in bronze match

3) N.Koreawin Asian Games football gold to repay Kim Jong-Un's love

4) Thai footballers miss Games bronze

5) Everton, Spurs on brink of Europa League last 32

6) Spain's Ferrer replaces injured Raonic in ATP Tour Finals

7) Women's tennis world number three Halep splits with coach

8) Federer humiliates Murray, Nishikori advances

9) India boxers refuses medal

10) Four Thai boxers eliminated

\section{DATA ANALYSIS}

In analyzing the multi - word expressions as used in the selected sport news stories, The following steps are followed.

1) All the selected sport news stories were carefully read.

2) The multi - word expressions used in the news stories were identified and written down.

3) The multi - word expressions used were classified based on the structures explained in chapter two.

4) The types of multi - word expressions which were used with the highest frequency were analyzed, calculated and presented in the table.

5) The findings were summarized and presented.

The steps described above can be illustrated in the chart below.

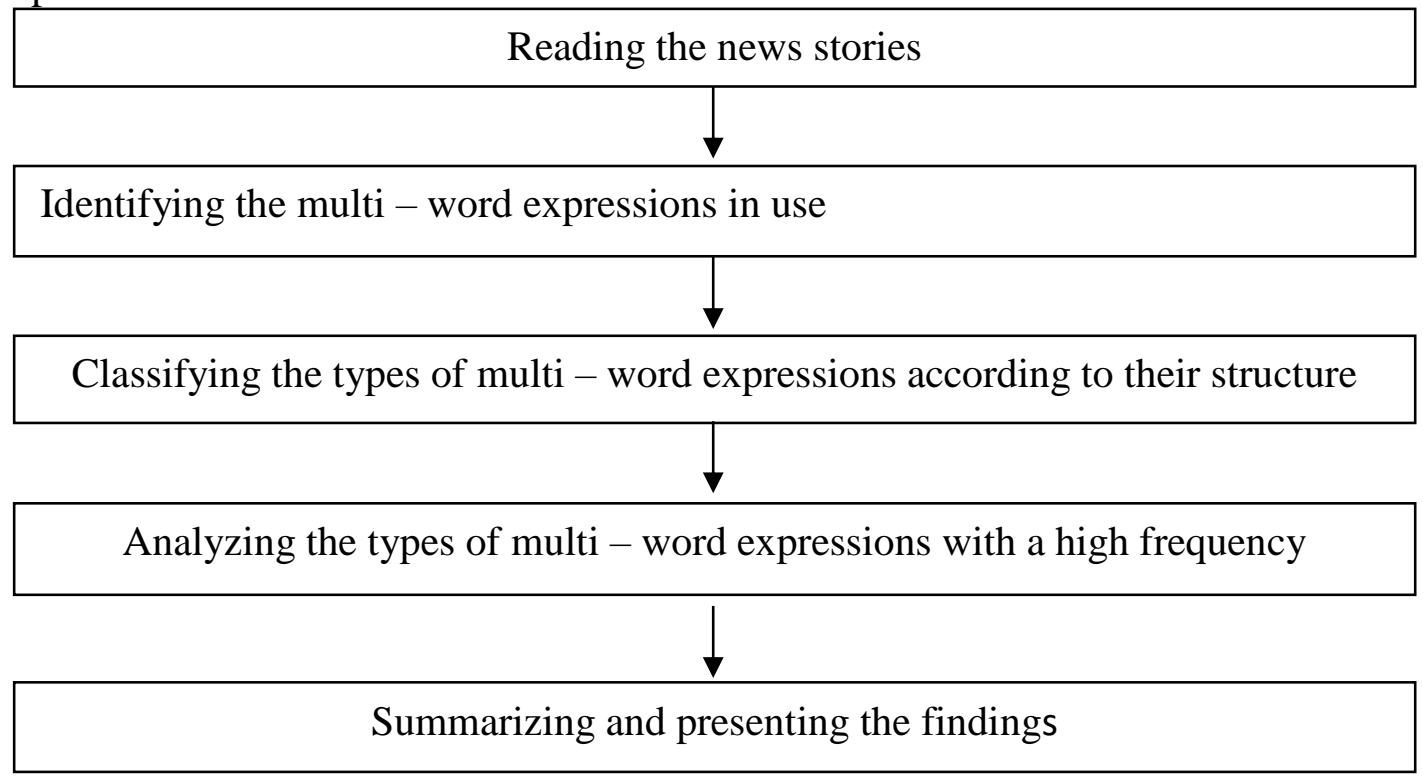


Ten selected sports news stories are analyzed based on the following structures of the multi-word expressions:

1) Adjective + Noun $=$ late penalty

2) Noun + Noun $=$ maiden appearance

3) Adjective + Noun + Noun = big sports fan

4) Noun + Noun + Noun $=$ Ubon Football Stadium

5) Noun + of + Noun $=$ best year of her career

6) Noun +'s + Noun = day's first final

\section{Sample:}

A first-half own goal by Tottenham Hotspur's Kyle Walker proved the difference as Manchester United opened their 2015-16 English Premier league campaign with a 1-0 victory at Old Trafford on Saturday.

The game's lone goal came in the 22nd minute when England right-back Walker, rushing back in an attempt to prevent Wayne Rooney talking aim from Ashley Young's cross, scuffed the ball into his own net.

It was the first time in history of English football's top flight that the first score of the season had come from an own goal.

Spurs made a bright start in the Salford sunshine, Christian Eriksen volleying over from Harry Kane's scooped pass, but they retreated into their shells following Walker's moment of misfortune.

An analysis of the Multi-Word Expression used can be analyzed as shown below.

\begin{tabular}{|c|c|c|}
\hline No. & Multi - Word Expression structure & Example \\
\hline 1 & Adjective + Noun & Own goal, lone goal, own net, top flight \\
\hline 2 & Noun + Noun & Salford sunshine, games percentage \\
\hline 3 & Adjective + Noun + Noun & big sports fan, valuable instruction team \\
\hline 4 & Noun + Noun + Noun & Incheon Football Stadium, Suzuki Cup team \\
\hline 5 & Noun + of + Noun & $\begin{array}{l}\text { The history of English football, moment of } \\
\text { misfortune }\end{array}$ \\
\hline 6 & Noun +'s + Noun & Ashley Young'cross, Spur's Walker \\
\hline
\end{tabular}

\section{RESULTS AND DISCUSSIONS}

The results section should provide details of all of the experiments that are required to support the conclusions of the paper. The section may be divided into subsections, each with a concise subheading.

It is advised that this section be written in past tense. It is a good idea to rely on charts, graphs, and tables to present the information. This way, the author is not tempted to discuss any conclusions derived from the study. The charts, graphs, and table should be clearly labeled and 
should include captions that outline the results without drawing any conclusions. A description of statistical tests as it relates to the results should be included.

\section{CONCLUSIONS \& RECOMMENDATIONS}

The purpose of the study was to analyze the structure and the type of the multi - word expressions used in selected sports news stories and examine the types of the multi-word expressions as used in the sports news stories. Ten sport new stories were selected in this study. They were five football news stories, three tennis news stories and two boxing newsstories. The news stories in the study were specifically taken from the Bangkok Post in November 2014. The multi-word expressions were analyzed based on the following structures: Adjective + Noun, Noun + Noun, Adjective + Noun + Noun, Noun +Noun + Noun, Noun + of + Noun, Noun +'s + Noun.

The study found that the patterns of the multi-word expressions which were used in the news stories can be detailed as follows. The structure which was used with the highest occurrence was Adjective + Noun, Asian Games; it account for $43.02 \%$ in ten news stories. The second most common was Noun + Noun, season-ending tournament; it accounts for $12.83 \%$. The structure which ranked third in its use in the selected news stories was Noun +'s+ Noun; Spain's Ferrer; it made up $18.11 \%$. The structure which came in fourth was Noun +of + Noun, Kuldep Singh of India; it presented $12.45 \%$. The structure which came in fifth was Noun +Noun + Noun, World number three; it presented $7.17 \%$. The structure of the multi-word expressions which was least used was Adjective +Noun+Noun, Five Thai fighters; it account for only $6.42 \%$ in ten selected news stories.

\section{DISCUSSION}

A multi - word expression is a lexeme made up of a sequence of two or more lexemes that has properties that are not predictable from the properties of the individual lexemes or their normal mode of combination. It is commonly used in English native speakers often use it in their writing. Thus, it is important for learners of English as a second language or a foreign language to understand the components of multi - word expressions if they want to figure out what is being said. A multi - word expression can be problematic to the English learners who have not well understood the structure. This is because the structure of the expression is quite long and it can pose a problem to the learners.

With a variety of patterns, a multi - word expression can positively contribute to the English learners understanding of the language if its components are understood.

The present study found that the structure of a multi - word expression which is most used is 'Adjective + Noun'. This may be because this structure is basic in English. The structure of English is familiar with 'Adjective + Noun' from the beginning.

Second in use is the structure of 'Noun +'s + Noun'. This structure is not too complex or long. Therefore, it is used with the second highest frequency.

The structure of a multi - word expression which is found at the lowest level is 'Adjective + Noun + Noun'. The possible explanation is that this structure is long and sometimes can be 
ambiguous to the receiver of the massage. Thus, it is avoided and not often used in the news stories under study.

In addition, as the newspaper especially in print has a limited space, it is thus necessary to make the best use of the space available. Also, the newspapers both online and in print have to deliver the information and message in a precise, succinct and direct manner. To save time and space, therefore, the multi-word expressions are preferred. The multi-word expressions which are used news stories can pose problems to learners or readers who are not familiar with the structure. The point made is in line with the study conducted by Barraclough, M. and Boonyavatana (1999) who found that the grammatical structure is very important to understanding the meaning of the text learners who lacked an understanding of the grammatical structure cannot fully understand the message of the text readBurken, H. A. (1976) also found that learners have to know the grammatical structure in order to get the information and meaning of the news.

\section{RECOMMENDATIONS}

\section{General recommendations}

- The multi-word expressions can be taught and learned by practicing how to analyze a short news story or a short passage selected from a text.

- Regular exercises on analyzing the multi - word expressions can enrich the learners' understanding of English.

\section{Recommendation for the further study}

- Further study can be conducted on the multi - word expressions as used in different sources, for example, science text, short stories, poems and social science texts.

\section{ACKNOWLEDGEMENTS}

The author wish to deeply thank all teachers and friends for their support, Dr. Prommintra Kongkaew, for his guidance and useful advice.

\section{REFERENCES}

[1] Agee, Warren K, Phillip H. Ault and Edwin Emery. Reporting and Writing the News. New York: Harper and Row, 1983, 412.

[2] Adult and Emery, Edwin, Phillip H. Introduction to Mass Communication. 3rded. New York: Dodd Mead, 1978, 142-150.

[3] Anchalee Veerachaisantikul. A Corpus Analysis of Multi Word Expressions in Newspapers A Case Study of The Bangkok Post. Master's Thesis, KhonKaen: KhonKaenUniversity, 2007.

[4] Barraclough, M. and Boonyavatana, P.English in Printed Media. English Department, Faculty of Humanities, Chiang Mai University. 1999.

[5] Baldwin, T\&. Bond, F. Multi Word Expression Using Cross Linguistic Corpora and Machine Learning Techniques. Retrieved April 8, 2005.

[6] Borden, D.L. Creative Writing Editing for Print Media. London: Wadsworth Publishing Company. 2008. 